\title{
Two new species of Platydoryctes Barbalho and Penteado-Dias, 2000 (Hymenoptera: Braconidae: Doryctinae) from Brazil, with an identification key for species
}

\author{
C. S. Castro ${ }^{a^{*}}$ (D) and A. M. Penteado-Dias ${ }^{a}$

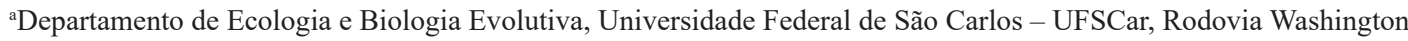 \\ Luis, Km 235, São Carlos, SP, Brasil \\ *e-mail: clovissormus@hotmail.com
}

Received: December 13, 2017 - Accepted: January 26, 2019 - Distributed: May 31, 2020

(With 15 figures)

\begin{abstract}
Platydoryctes Barbalho and Penteado-Dias 2000 is a small genus of Neotropical parasitoid wasps (Hymenoptera: Braconidae: Doryctinae) with four described species to date. Two new species of the genus are described from Brazil, and a key to species is presented in this paper.
\end{abstract}

Keywords: biodiversity, ichneumonoidea, neotropical, parasitoid wasp, taxonomy.

\section{Duas novas espécies de Platydoryctes Barbalho e Penteado-Dias, 2000 \\ (Hymenoptera: Braconidae: Doryctinae) do Brasil, com uma chave de identificação para espécies}

\begin{abstract}
Resumo
Platydoryctes Barbalho and Penteado-Dias 2000 é um pequeno gênero Neotropical de vespas parasitoides (Hymenoptera: Braconidae: Doryctinae), com quatro espécies descritas até o presente. Duas novas espécies do gênero são descritas para o Brasil e uma chave para espécies é apresentada neste trabalho.
\end{abstract}

Palavras-chave: biodiversidade, ichneumonoidea, neotropical, parasitoid wasp, taxonomy.

\section{Introduction}

Erected in the year 2000, Platydoryctes Barbalho and Penteado-Dias, 2000 is a neotropical genus, initially containing four species, being one of them (Platydoryctes amazonensis Barbalho and Penteado-Dias, 2000) transferred by Marsh (2002) to the genus Angelica Marsh, 2002. All remaining species are found in Brazil: Platydoryctes duckensis Barbalho and Penteado-Dias, 2000, from Amazonas and Rondônia states; Platydoryctes rafaeli Barbalho and Penteado-Dias, 2000, from Rondônia state; and Platydoryctes soaresi Barbalho and Penteado-Dias, 2000, from Santa Catarina and São Paulo states. Platydoryctes duckensis is also found in Costa Rica, at Guanacaste Province (Marsh, 2002). This genus is characterized mainly by its dorsoventrally flattened body (Barbalho and Penteado-Dias, 2000).

Here, with the aim of improving our knowledge about the group, we described two new species of Platydoryctes from Brazil: Platydoryctes corumba Castro and Penteado-Dias sp. nov. (Mato Grosso do Sul State, Brazilian midwest), and Platydoryctes mossoro Castro and Penteado-Dias sp. nov. (Rio Grande do Norte State, Brazilian northeast).

\section{Methods}

The terminology employed to morphological features follows Sharkey and Wharton (1997), except for the term "precoxal sulcus" which replaces "sternaulus" Wharton (2006). Surface sculpture nomenclature follows Harris (1979). The following abbreviations are employed: POL-postocellar line; OOL-ocular-ocellar line; Od-maximum diameter of lateral ocellus.

The specimens were collected in Corumbá, Mato Grosso do Sul state, using light and Malaise traps. The genus was identified using Marsh (2002) and for species we used Barbalho and Penteado-Dias (2000) and Marsh (2002). Images were taken with a Leica DFC 295 video camera attached to a Leica M205C with a Planapo 1.0x objective. Figures were produced from stacks of images using LAS (Leica Application Suite) v3.7. The uncoated specimens were illustrated and analyzed through a Scannig Electron Microscope (SEM, FEI Quanta 250) in low-vacuum mode. Types are deposited at DCBU collection (Coleção Entomológica do Departamento de Ecologia e Biologia Evolutiva da Universidade Federal de São Carlos, São Carlos, São Paulo, Brazil). 


\section{Results and Discussion}

\subsection{Systematics}

\subsubsection{Platydoryctes Barbalho and Penteado-Dias 2000}

Platydoryctes Barbalho and Penteado-Dias 2000: 26, 27, 30; Marsh 2002: 52; 176.

Type species: Platydoryctes soaresi Barbalho and Penteado-Dias 2000

Diagnosis. Platydoryctes is very similar to Callihormius but is distinguished by the flattened body and the longer acrosternite (at least 0.5 or more length than first metasomal tergum).

Hosts. Unknown.

Distribution. Brazil and Costa Rica.

Key to species of Platydoryctes Barbalho and Penteado-Dias (modified from Barbalho and Penteado-Dias, 2000)

1. Hind wing vein $\mathrm{M}+\mathrm{CU}$ longer than vein $1 \mathrm{M} \ldots \ldots \ldots .2$

- $\quad$ Hind wing vein $\mathrm{M}+\mathrm{CU}$ equal or shorter than vein $1 \mathrm{M}$... 4
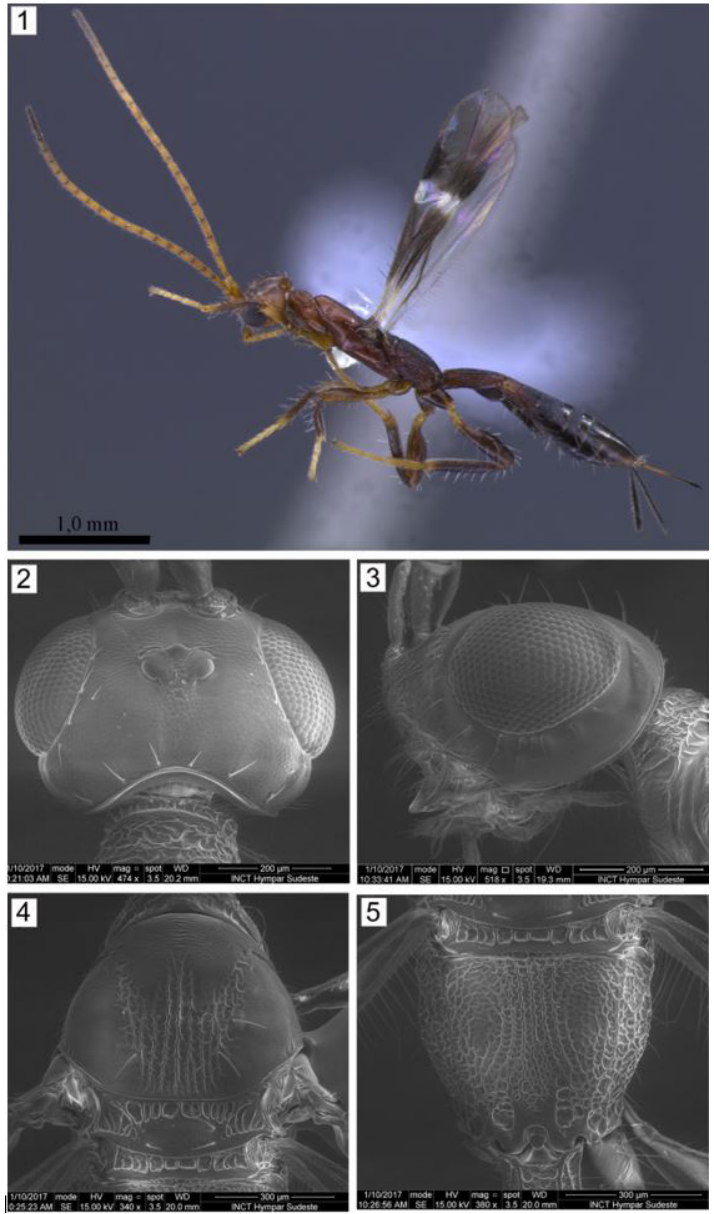

Figure 1-5. Platydoryctes corumba Castro and Penteado-Dias sp. nov. 1 , habitus; 2 , head, dorsal view; 3 , head, lateral view; 4 , mesoscutum, dorsal view; 5 , propodeum, dorsal view.
2. Frons and vertex smooth; fore wing vein $r$ equal or longer than vein $3 \mathrm{RSa}$

duckensis Barbalho and Penteado-Dias

- Frons and vertex coriaceous; fore wing vein r 0.5-0.75 times longer than 3RSa ........................ 3

3. Head in dorsal view 2.6 times longer than width; propodeumlongitudinallystrigate-rugose(Figures 1-10); ovipositor cutting straight corumba Castro and Penteado-Dias sp. nov.

- Head in dorsal view 1.6 times longer than width; propodeum carinate dorsally, rugose laterally (Figures 1-10); ovipositor cutting curved ............. mossoro Castro and Penteado-Dias sp. nov.

4. Head 1.2 times longer than width; temple smooth soaresi Barbalho and Penteado-Dias

- Head 2 times longer than width; temple granulate rafaeli Barbalho and Penteado-Dias
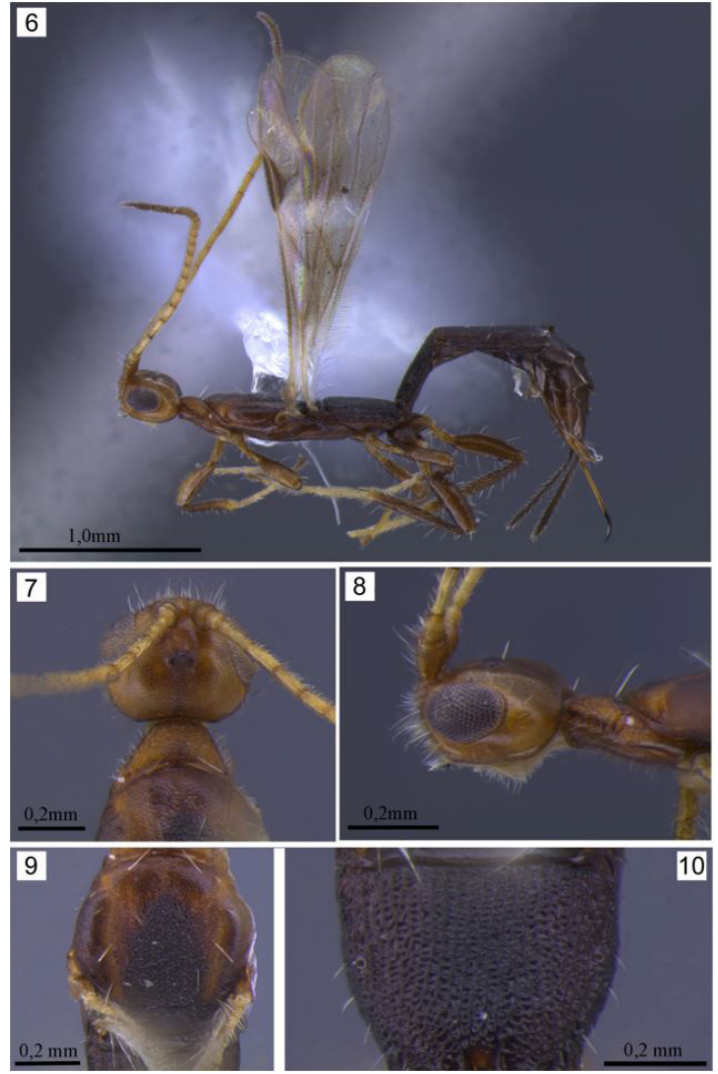

Figure 6-10. Platydoryctes mossoro Castro and Penteado-Dias sp. nov. 6 , habitus; 7 , head, dorsal view; 8 , head, lateral view; 9 , mesoscutum, dorsal view; 10 , propodeum, dorsal view. 
3.1.2. Platydoryctes corumba Castro and Penteado-Dias, sp. nov.

Material examined. Holotype. Female (DCBU): "Sisbiota - Corumbá, MS, BEP, Malaise 3, 190 34' 30.5"N; $57^{\circ} 00^{\prime}$ 50.6”W, 31/I/2012, Lamas \& Nihei cols." Paratypes. Four females, "Sisbiota-Corumbá, MS, BEP, Malaise 3, 190 34'30.5”N, 57 00' 50.6”'W, 01/I/2012, Lamas \& Nihei cols."

Diagnosis. Platydoryctes corumba sp. nov. (Figure 1) is similar to Platydoryctes mossoro in having hind wing vein $\mathrm{M}+\mathrm{CU}$ longer than vein $1 \mathrm{M}$ and mesoscutum carinate-rugose centrally, differing from it by its head in dorsal view 2.6 times longer than width (1.6 times longer than width in P. mossoro); propodeum strigate-rugose, (carinate dorsally, rugose laterally in $P$. mossoro, and ovipositor cutting straight (ovipositor cutting curved in P. mossoro).

Description. Female. Body length 3.1-3.3 mm; fore wing length 1.9-2.0 mm; ovipositor length 0.3-0.5 mm.

Head: Head in dorsal view 2.6 times wider than its median length, as wide as width of mesoscutum. Transverse diameter of eye in lateral view 1.4 times longer than temple. Ocelli arranged in an isosceles triangle. POL 2.2 times as long as Od, 0.9 times to OOL. Eyes, 1.3 times as high as width. Height of malar space around 0.3 times height of eye. Malar suture absent. Hypoclypeal depression rounded, as long as wide. Occipital carina complete, ventrally joined with hypostomal carina. Antenna with 22 antennomeres. Scape 1.8 times longer than its maximum width, first flagellar segment straight, 5.0 times longer than apical width, 1.2 times longer than second segment.

Mesosoma: Length of mesosoma 4.5 times its height. Pronotum with medial pronotal groove. Notauli present anteriorly. Pre-scutellar depression in dorsal view deep, with eight carinae clearly defined, about 0.2 times as long as scutellum. Scutellum flattened.

Wings: fore wing 4.1 times longer than its maximum width. Pterostigma 3.3 times longer than wide. Vein $r$ arising before of the middle of pterostigma. Marginal cell long, its length 2.8 times maximum width. Vein R1 1.3 times longer than pterostigma. Vein $r$ as long as maximum width of pterostigma. Vein 3RSa straight; 1.8 times longer than vein $\mathrm{r}$; 0.9 times as long as vein $2 \mathrm{RS}$. Vein $2 \mathrm{RS} 1.5$ times longer than vein $r$; 3.4 times longer than vein $\mathrm{m}-\mathrm{cu}$. Vein $\mathrm{m}$-cu in line with vein $2 \mathrm{RS}$. Vein (RS+M)a slightly curved. First discal cell 0.5 times as long as wide. Veins $1 \mathrm{M}$ parallel to $\mathrm{m}-\mathrm{cu}$. Vein $1 \mathrm{M} 5.0$ times longer than vein $\mathrm{m}$-cu. Vein cu-a straight, post-furcal with vein $1 \mathrm{M}$. Vein $\mathrm{M}+\mathrm{CU}$ curved. First subdiscal cell open distally, vein $2 \mathrm{cu}-\mathrm{a}$ absent. Hind wing 5.8 times longer than wide. Vein $\mathrm{SC}+\mathrm{R}$ 1.2 times as long as vein $\mathrm{C}+\mathrm{SC}+\mathrm{R}$. Basal cell narrow, its length 9.7 times maximum width, 0.2 times as long as length of wing. Vein M+CU 2.2 times longer than vein $1 \mathrm{M}$.

Legs: Fore tibia with a row of seven spines arranged more or less in line. Hind coxa 1.5 times longer than its maximum width. Hind tarsus as long as hind tibia. Basitarsus 0.8 times as long as second-fifth tarsal segments combined. Second tarsal segment 0.4 times as long as basitarsus, 1.5 times as long as fifth segment (without pretarsus).

Metasoma: Metasoma as long as head and mesosoma combined. Maximum width of first tergite 1.5 times its minimum width, as long as propodeum. Median length of second tergite 0.7 times as long as its basal width, 1.1 times length of third tergite. Combined length of second and third tergites 0.7 times as long as their maximum width. Ovipositor sheaths 0.3 times as long as metasoma, 0.4 times as long as mesosoma, 0.3 times as long as fore wing, 0.8 times as long as hind tibia.

Sculpture and pubescence: Head with face smooth with setae, with an elevated and weakly costate area centrally, clypeus and mandibles smooth and with setae, frons and vertex coriaceous (Figure 2), temple coriaceous and gena smooth (Figure 3). Pronotal collar scrobiculate, pronotal groove shallow and scrobiculate; pronotum coriaceous and smooth below pronotal groove. Mesoscutal lobes coriaceous (Figure 4). Notauli not joining posteriorly and scrobiculate anteriorly, meeting scutellum in a carinate-rugose area. Scutellum coriaceous. Mesopleuron smooth, subalar sulcus coriaceous and smooth on border with tegula, pre-coxal sulcus smooth. Metapleuron rugose. Propodeum longitudinally strigate-rugose centrally, areolate-rugose laterally (Figure 5). Legs coriaceous, with sparse setae. First metasomal tergite carinate-rugose; second metasomal tergite carinate, third and fourth metasomal tergite carinate basally, smooth apically; fifth metasomal tergite areolate basally and smooth apically. Remaining tergites smooth to weakly coriaceous.

Color: Head yellow, except stemmaticum black. Scape, pedicel and flagellomeres yellow, except four first apical flagellomeres blackish. Mesosoma and mesoscutal lobes brownish, central area of mesoscutum, scutellum, propodeum and tegula blackish. Legs brown, except fore and middle coxae, trochanter, trochantellus and tarsi yellow; hind coxa apically, trochanter, trochantellus, and tarsi yellow. Metasoma brownish with first and second metasomal tergites lighter. Ovipositor brown with cutting sheaths black.

Material examined. Holotype. Female (DCBU): "Sisbiota-Corumbá, MS, BEP, Malaise 3, $19^{0} 34$ ' 30.5"N; $57^{0} 00$ ' 50.6”W, 31/I/2012, Lamas \& Nihei cols." Paratypes. Four females, "Sisbiota - Corumbá, MS, BEP, Malaise $3,19^{0} 34^{\prime} 30.5^{\prime} \mathrm{N}, 57^{0} 00^{\prime} 50.6$ ' $\mathrm{W}, 01 / \mathrm{I} / 2012$, Lamas \& Nihei cols."

Male. Unknown.

Distribution. Corumbá, Mato Grosso do Sul State, Midwestern Brazil.

Biology. Unknown.

Etymology. The name of this species refers to the locality where the type specimen was collected.

\subsubsection{Platydoryctes mossoro Castro and Penteado-Dias,} sp. nov.

Diagnosis. Platydoryctes mossoro sp. nov. (Figure 6) is similar to Platydoryctes duckensis by its hind wing vein $\mathrm{M}+\mathrm{CU}$ longer than vein $1 \mathrm{M}$ and mesoscutum carinate, differing by it vertex coriaceous (vertex smooth in P. duckensis) and propodeum dorsally carinate (propodeum rugose in $P$. duckensis). It is also similar with $P$. corumba in having hind wing vein $\mathrm{M}+\mathrm{CU}$ longer than vein $1 \mathrm{M}$ and mesoscutum carinate-rugose centrally, differing from it by its head in dorsal view 1.6 times longer than width (2.6 times longer than width in P. mossoro); propodeum carinate dorsally, rugose laterally (strigate-rugose in 
P. mossoro) and ovipositor cutting curved (ovipositor cutting straight in P. mossoro).

Description. Female. Body length $3.4 \mathrm{~mm}$; fore wing length $1.9 \mathrm{~mm}$; ovipositor length $0.5 \mathrm{~mm}$.

Head: Head width 1.6 times median length (dorsal view), as long as width of mesoscutum. Transverse diameter of eye 1.7 times longer than temple. Ocelli arranged in an isosceles triangle. POL as long as to Od, 0.5 times to OOL. Eye glabrous, 0.8 times as high. Head as width. Height of malar space around 0.5 times height of eye. Malar suture absent. Hypoclypeal depression rounded, as long as wide. Occipital carina complete, ventrally joined with hypostomal carina. Antenna with 20 antennomeres. Scape 1.7 times longer than its maximum width, first flagellar segment straight, 4.0 times longer than apical width, as long as second segment.

Mesosoma: Length of mesosoma 5.6 times its height. Pronotum with medial pronotal groove. Mesoscutum not declivous anteriorly and on nearly same line of pronotal collar (lateral view); its length (dorsal view) is 1.5 times as long as its maximum width. Notauli absent. Pre-scutellar depression deep, with eight carinae clearly defined, about 0.2 times as long as scutellum. Scutellum flattened. Metapleural lobe large.

Wings: fore wing 4.0 times longer than its maximum width. Pterostigma large, 2.8 times longer than wide. Vein $r$ arising before middle of pterostigma. Marginal cell long, its length 2.7 times maximum width. Vein R1 1.1 times longer than pterostigma. Vein $\mathrm{r} 0.7$ times as long as maximum width of pterostigma. Vein 3RSa straight in its length, 1.5 times longer than vein $\mathrm{r}, 0.5$ times longer than vein $2 \mathrm{RS}$. Vein 2RS 2.7 times longer than vein r, 4.0 times longer than vein $\mathrm{m}$-cu. Vein $\mathrm{m}$-cu in line with vein $2 \mathrm{RS}$. Vein $(\mathrm{RS}+\mathrm{M}) \mathrm{a}$ straight. First discal cell 0.5 times longer than width. Veins $1 \mathrm{M}$ parallel to $\mathrm{m}-\mathrm{cu}$. Vein $1 \mathrm{M} 6.3$ times longer than vein $\mathrm{m}$-cu. Vein cu-a straight, slightly post-furcal with vein $1 \mathrm{M}$. Vein $\mathrm{M}+\mathrm{CU}$ slightly curved. First subdiscal cell open distally, vein 2cu-a absent. Hind wing 9.8 times longer than wide. Vein $\mathrm{SC}+\mathrm{R} 1.1$ times longer than $\mathrm{C}+\mathrm{SC}+\mathrm{R}$. Basal cell narrow, its length 8.5 times maximum width, 0.2 times length of wing. Vein $\mathrm{M}+\mathrm{CU} 2.2$ times longer than vein 1M. Vein m-cu straight.

Legs: Fore tibia with a row of six spines arranged more or less in a line. Hind coxa without basoventral tubercle, 1.6 times longer than its maximum width. Hind tarsus as long as hind tibia. Basitarsus 0.8 times as long as second-fifth segments combined. Second tarsal segment 0.5 times as long as basitarsus, 2.2 times as long as fifth segment (without pretarsus).

Metasoma: Metasoma 1.4 times longer than head and mesosoma combined. Maximum width of first tergite 2.4 times its minimum width, 1.3 times longer than propodeum. Median length of second tergite as long as its basal width, 1.3 times length of third tergite. Combined length of second and third tergites 1.1 times their maximum width. Ovipositor sheaths 0.3 times as long as metasoma, 0.4 times as long as mesosoma, 0.1 times as long as body, 0.3 times as long as fore wing, 0.8 times as long as hind tibia.
Sculpture and pubescence: Head with face smooth with setae, with an elevated and weakly costate area centrally, clypeus and mandibles smooth and with setae, frons and vertex coriaceous (Figure 7), temple and gena smooth (Figure 8). Pronotal collar rugose; pronotum rugose. Mesoscutal lobes coriaceous. Mesoscutum centrally carinate-rugose (Figure 9). Scutellum coriaceous. Mesopleuron smooth, subalar sulcus smooth and weakly coriaceous on border with pronotum and tegula, pre-coxal sulcus weakly scrobiculate. Metapleuron areolate-rugose. Propodeum carinate and without any carinae (Figure 10). Legs coriaceous, with sparsely setae. First metasomal tergite carinate-rugose with wing-like flanges; second metasomal tergite carinate, third metasomal tergite carinate basally and smooth at central-apical area; fourth metasomal tergite punctate basally, smooth apically; fifth metasomal tergite areolate-rugose basally and smooth apically; eight and tenth metasomal tergites weakly coriaceous. Remaining tergites smooth.

Color: Head yellow, except stemmaticum black. Scape, pedicel and flagellomeres yellow, except five first apical flagellomeres blackish. Mesosoma brownish, except pronotal collar and mesoscutal lobes yellowish, central area of mesoscutum, scutellum and propodeum black; tegula yellow. Legs brown, except all trochanter, trochantellus and tarsi light yellow. Metasoma brownish from darker first tergites to lighter. Ovipositor brown with cutting black and its sheaths black.

Material examined. Holotype. Female (DCBU): "Mossoró, RN, Brasil, Fazenda Santa Júlia, Armadilha Malaise 1, 03/X/2007, D.R.R. Fernandes col."

Male. Unknown.

Distribution. Mossoró, Rio Grande do Norte State, Northeastern Brazil.

Biology. Unknown.

Etymology. The name of this species refers to the locality where the type specimen was collected.

\section{Acknowledgements}

We are grateful to CAPES (Coordenação de Aperfeiçoamento de Pessoal de Nível Superior), CNPq (Conselho Nacional de Desenvolvimento Científico e Tecnológico), FAPESP (Fundação de Amparo à Pesquisa do Estado de São Paulo) and INCT- Hympar (Instituto Nacional de Ciência e Tecnologia dos Hymenoptera parasitoides) for financial support; to Luciana B.R. Fernandes, biologist of DEBE/UFSCar, for taking the SEM and stereomicroscope photographs; to reviewers of the manuscripts.

\section{References}

BARBALHO, S.M. and PENTEADO-DIAS, A.M., 2000. Platydoryctes, a new Doryctinae genus from Brazil (Hymenoptera, Braconidae). Entomological News, vol. 111, no. 1, pp. 25-31.

HARRIS, R.A. 1979. A glossary of surface sculpturing. Occasional Papers in Entomology, vol. 28, pp. 1-31. 
MARSH, P.M., 2002. The Doryctinae of Costa Rica (excluding the genus Heterospilus). Memoirs of the American Entomological Institute, vol. 70, pp. 1-319.

SHARKEY, M.J. and WHARTON, R.A. 1997. Morphology and terminology. In: WHARTON, R.A., MARSH, P.M., SHARKEY, M.J., eds. Manual of the New World genera of the family Braconidae
(Hymenoptera). Washington: International Society of Hymenoptera, pp. 21-40. Special Publication, no. 1.

WHARTON, R.A., 2006. The species of Sternaulopius Fischer (Hymenoptera: Braconidae, Opiinae) and the braconid sternaulus. Journal of Hymenoptera Research, vol. 15, pp. 317-347. 